\title{
"A INCLUSÃO NA VIDA COMO NAS BIBLIOTECAS DEVE SER PAUTADA PELA CONVIVÊNCIA", DIZ O ESCRITOR EMÍLIO FIGUEIRA
}

Por Danielle da Silva Pinheiro Wellichan ${ }^{1}$

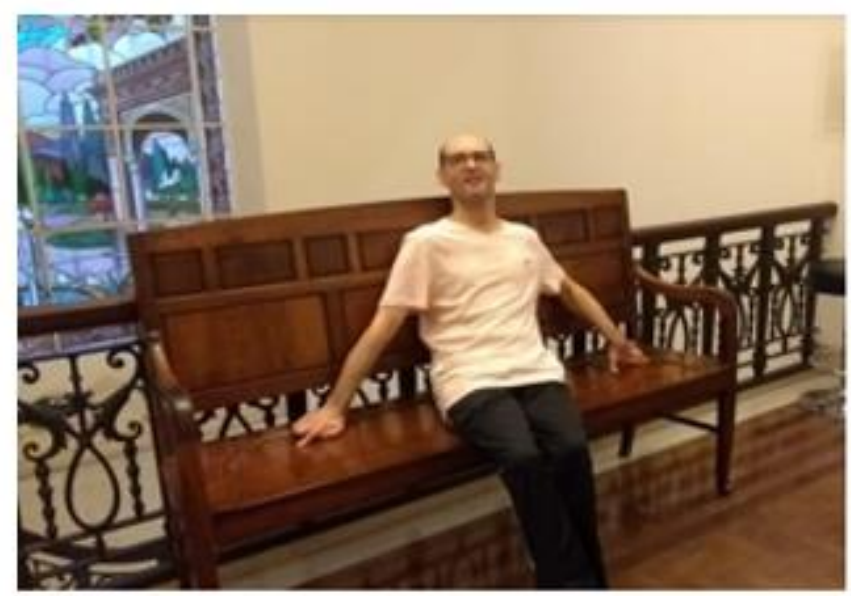

Fonte: Acervo pessoal do Escritor

Por causa de uma asfixia durante o parto, em 1969, Emílio Figueira sofreu uma paralisia cerebral, com sequelas na fala e movimentos. Nunca se deixou abater por sua deficiência motora e vive intensamente inúmeras possibilidades. Nas artes, no jornalismo, autor de uma vasta produção científica, é psicólogo, psicanalista, teólogo independente. Com cinco graduações e dois doutorados, Emílio Figueira foi professor e conferencista de pós-graduação, principalmente de temas que envolvem a Educação Inclusiva ou psicologia das pessoas com deficiência.

Como escritor, é dono de uma variada coleção de livros impressos e digitais, passando de 70 títulos lançados. Atualmente, dedica-se a escrever roteiros audiovisuais e ficção. Como romancista e criador do estilo "romance polimático", Emílio Figueira tem disponibilizado gratuitamente seus folhetins na plataforma Wattpad.

Conheci o Emílio quando trabalhei na biblioteca da universidade na qual ele estudava. Sempre foi aquele usuário-amigo, que a gente adora receber: atencioso, gentil, estudioso. Sempre passava na biblioteca, mesmo que fosse para dizer um oi e todos (TODOS) adoravam encontrá-lo. Quando ele se formou, fez uma doação enorme para a biblioteca: livros novos e atuais, de diferentes temas, que utilizou durante a faculdade. Queria compartilhar o que foi importante para ele.

Não foi só ele que acolheu a biblioteca, a biblioteca o acolheu! Tornou-se uma parte dali. Não raramente, quando os estudantes se formam e vão embora, nós, bibliotecários, sentimos aquela alegria pela vitória deles, mas também um vazio de saudade, afinal grandes amizades nascem nas bibliotecas. E mesmo depois de sua mudança de cidade, essa amizade nunca se perdeu. Seus textos e livros me

\footnotetext{
1 Bibliotecária e Pedagoga Especialista, Mestre em Ciência da Informação (UNESP/Marília) e Doutoranda em Educação, na linha de Educação Especial (UNESP/Marília). Membro do Grupo de Pesquisa DeFSen - Deficiências Físicas e Sensoriais (UNESP/ Marilia) e do GT Acess Acessibilidade em Bibliotecas - FEBAB. Contato: dany_unesp@yahoo.com.br
} 
mantinham perto de suas ideias, as redes sociais me possibilitaram encontrá-lo novamente e, entre um trabalho e outro, conversar sobre um assunto de grande importância: os usuários com deficiência, nas bibliotecas.

Embora seja um tema ainda pouco abordado, estamos buscando mais proximidade, e ações estão sendo realizadas nesse sentido na Biblioteconomia. Mas nada como bater um papo para conhecer melhor sobre essa relação. Então, compartilho com vocês, pois não poderia guardar só para mim.

\section{Conte como é a sua relação com as bibliotecas}

EMíLIO: Desde pequeno, eu tive uma relação muito íntima com as bibliotecas públicas. Amava frequentá-las, caminhar entre as prateleiras. Na época da escola então, ainda não existia o computador e a internet. A gente precisava fazer pesquisas e trabalhos escolares, passar muitas horas sentados copiando trechos de livros, enciclopédias, atlas, enfim. E isso era feito tanto sozinho como em grupo. Minhas frequências às bibliotecas eram tantas e praticamente diárias, uma enorme vontade de estar nesses ambientes mágicos para mim. Eu cultivava naturalmente amizades com os atendentes, os quais já estavam sempre prontos para me atender, auxiliar-me por causa de minha deficiência motora.

Com certeza, essa minha relação desde pequeno com as bibliotecas e os livros foi um dos fatores decisivos à minha carreira de escritor. E tem outro detalhe. Eu sempre ganhei e comprei muitos livros. De tempos em tempos, eu junto meu acervo, identifico uma biblioteca, pública ou de faculdade, e faço doações. Acredito que o conhecimento deve estar, cada vez mais, à disposição de um número maior de pessoas, não só para mim, dentro de meu escritório.

\section{Como você percebe as bibliotecas quanto ao atendimento de pessoas com deficiência na atualidade?}

EMílIO: Com certeza, ao longo dos anos e devido às políticas inclusivas, as bibliotecas foram se modificando, adaptando-se para atender e oferecer facilidades de acesso e acessibilidade para as pessoas com deficiência. Mas nem todas as bibliotecas estão atentando para isso. Vejo que as bibliotecas públicas, talvez por obrigação de cumprir a lei, estão se adequando muito mais à inclusão do que os particulares. Por exemplo, há uma universidade tradicional e renomada, aqui em São Paulo, cuja consulta ao acervo ainda é feita em antigas fichas datilografadas em máquinas de escrever. Quero dizer com isso que, se ela ainda nem se quer informatizou seu acervo, não tem nem como oferecer pesquisas informatizadas e equipamentos de recursos para qualquer usuário, tenha deficiência ou não.

Só que existem também as questões das bibliotecas públicas de pequenos municípios, de escolas de regiões humildes, de igrejas, de mosteiros, dentre outras, que mal tem recursos para suas sobrevivências, menos ainda para promover adaptações inclusivas, ampliar seus espaços físicos e acervo. É algo que precisamos começar a nos atentar. 


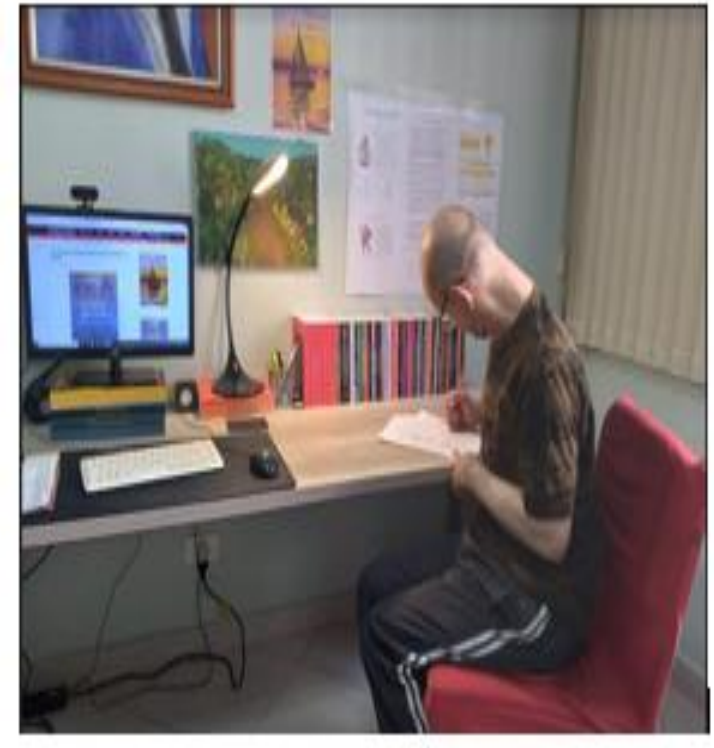

Fonte: Acervo pessoal do Escritor
Conheça as obras de Emílio

Figueira sobre literatura, memórias, poesia, infanto-juvenil, artes plásticas, textos teatrais, didáticos, psicologia e psicanálise, inclusão, educação inclusiva, reabilitação, memórias e ficção, obras traduzidas, dramaturgia e produção audiovisual.

Acesse:

https://www.emiliofigueira.com.br linktr.ee/emiliofigueira

Nas bibliotecas, você percebe "barreiras" que possam dificultar o acesso, o uso e a frequência de um usuário com deficiência? Quais seriam elas?

EMÍLIO: As bibliotecas precisam ter equipamentos de Tecnologia Assistiva e pessoas que saibam usá-las para auxiliar os usuários que delas necessitam, assim como outros serviços específicos para uma pessoa com deficiência: equipes treinadas em Libras, entrosamentos, treinamentos, orientações que eliminem as dificuldades e promovam a comunicação com a equipe da biblioteca, o que facilitará a comunicação de usuários com ou sem deficiência. Ter materiais acessíveis, como livros e textos em Braille, por exemplo. Precisamos eliminar muitas das barreiras arquitetônicas, como: o espaço pequeno entre as estantes de livros, que impedem a circulação de cadeirantes; catracas na entrada da biblioteca; oferecer mais serviços digitais, tanto no local quanto consultas online ao acervo.

\section{O que você considera mais importante para uma biblioteca que deseja oferecer um ambiente inclusivo?}

EMÍLIO: É importante termos equipamentos, capacitação, materiais acessíveis, acessibilidade estrutural, serviços digitais, sinalização. Mas o que vou dizer aqui serve para qualquer biblioteca, seja grande, pequena, tenha adaptações ou não: ao receber um usuário que tenha alguma deficiência ou outra particularidade, antes de qualquer recurso, pesquise na própria pessoa qual é sua necessidade. Ou seja, estabeleça inicialmente um diálogo aberto e simpático com ela. Ninguém melhor do que o próprio usuário para explicar como ele precisa e quer ser ajudado.

\section{Um atendimento inclusivo em uma biblioteca, em sua opinião, como deveria ser?}

EMÍLIO: Vou repetir o que disse anteriormente: além de todos os recursos tecnológicos e humanos, conviva de forma descontraída com todos os usuários, com ou sem deficiência. A partir daí, todo o atendimento ocorrerá naturalmente, como 
sempre foi minha relação com os bibliotecários. Aliás, em todas minhas obras, sempre defendi que inclusão é convivência!

Ouvir nossos usuários da informação e torná-los parte dos nossos processos é o caminho para a inclusão nas bibliotecas! 